\title{
Gold in Hybrid Microelectronics
}

\section{THE COMPLEMENTARY USE OF THIN AND THICK FILM INTEGRATED CIRCUITS}

\author{
R. F. Russell \\ ITT Components Group Europe, Paignton, Devon, England
}

Thin film and thick film circuits represent two important and high volume applications of gold in the electronics industry. This article reviews the techniques used in these fields by one major manufacturer to meet the requirements of high performance, small size and reliability.

The variety of methods of using gold in electronics implies a wide range of techniques. Many organisations specialise in one or other of them but, as might be expected from part of one of the world's largest companies in the field of telecommunications, ITT Components Group Europe has interested itself in all of them, and its Film Circuit Operation at Paignton in Devon uses both thin and thick film techniques on a considerable scale.

\section{Thin Film Technology}

The natural advantages of gold in electronics reside in its total resistance to tarnishing and corrosion at all operating temperatures and in all environments to which circuits are exposed, in its high electrical conductivity, and in its relative ease of deposition by various techniques.

Thin film technology for electronic circuit manufacture comprises a range of vacuum deposition processes such as evaporation, sublimation and sputtering which enable thin films $(<10 \AA)$ of conductive, resistive, insulating and in some cases semiconducting materials to be deposited on to an insulating passive substrate. These materials form the basis for the fabrication of the electrical elements resistors, conductors and capacitors.

Gold and its alloys feature prominently in the range of suitable conductor materials, being readily deposited by sputtering or evaporation, and capable of producing high conductivity thin film interconnections and terminations to which reliable welded or soldered connections can be made.

Thin film techniques have been used at Paignton for some twelve years. The activity commenced with the development of a silica thin film capacitor produced by reactive sputtering (1). The capacitor had aluminium electrodes and was terminated by chromium-gold conductors. The expertise gained in
Fig. 1 Thin film master substrate containing a stepped and repeated pattern. Each circuit comprises nickelchromium resistors and a chromium-gold interconnection pattern deposited on a borosilicate glass substrate

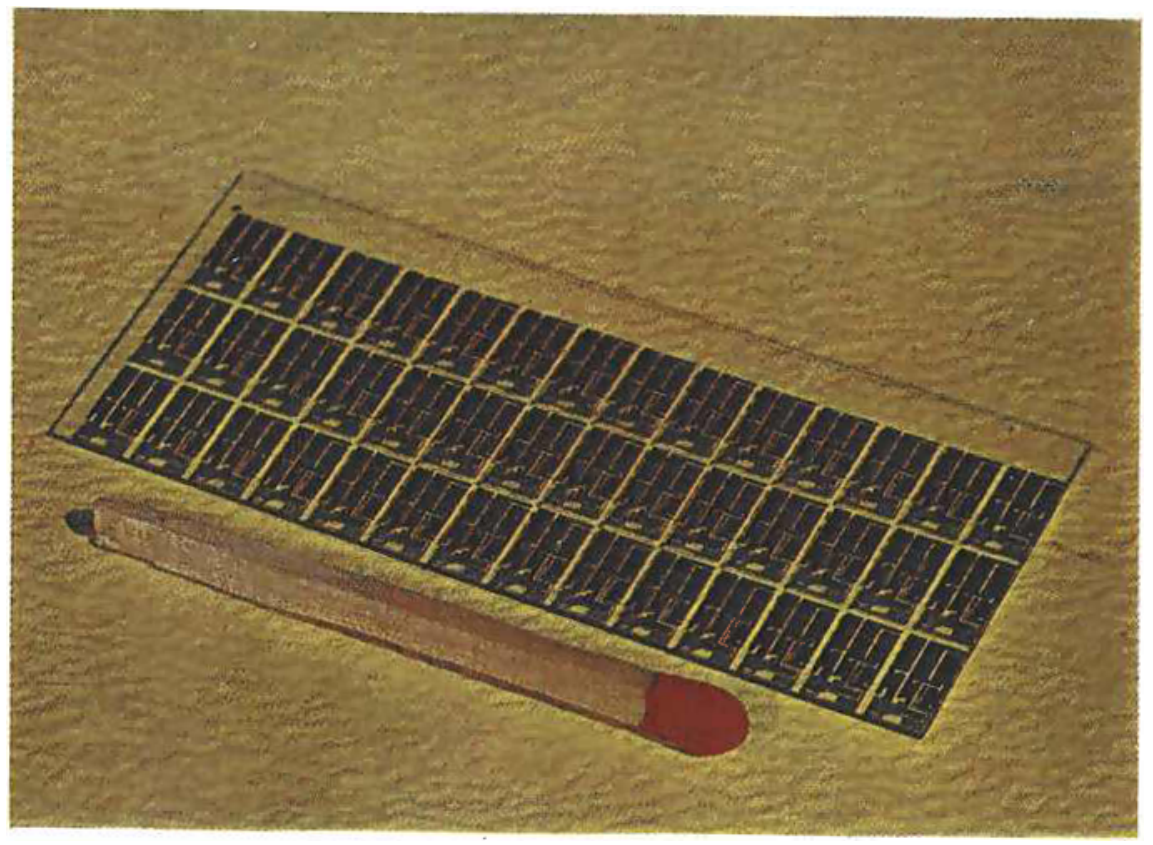


Fig. 2 Examples of thin film substrates showing various combinations of resistors, capacitors and chromium. gold interconnection

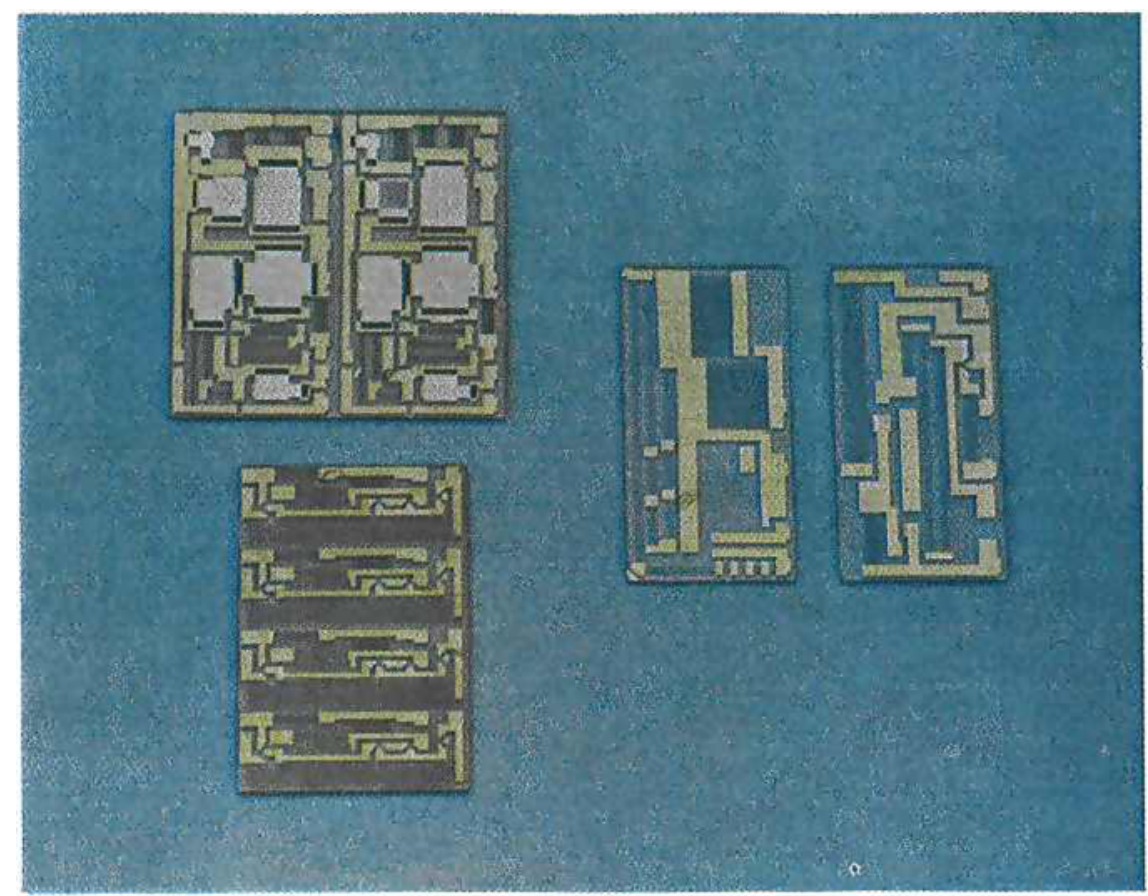

vacuum technology led to the development of a nickel-chromium resistor system, sublimed on to borosilicate glass substrates as shown in Fig. 1. The CrAu conductor film was proved to give a stable ohmic contact to the resistors, and provided full interconnection and termination of the resistor/capacitor film network as shown in Fig. 2.

The chromium-gold conductor is composed of three major layers. Initially the chromium is deposited by sublimation from granules to give a highly adherent coating to the glass substrate. The gold deposition is then started using evaporation from the molten metal so that vapour phase mixing of the gold and the chromium occurs, depositing a film of the alloy. The chromium deposition is then terminated and the pure gold evaporation continued in order to generate the low resistivity and bondability required. The thickness of the total gold film is $\sim 1 \mu$.

Patterning techniques for the resistor material have evolved throughout this period, from stencil masking and photolithography to computer controlled microengraving (2). Microengraving is an important technique as it enables both patterning and resistor adjustment to be performed.

The first major breakthrough in the techniques resulted from work carried out by our associated laboratories, Standard Telecommunication Laboratories Ltd. They developed a spark machining technique which controlled a capacitor discharge into the resistor film. By moving the substrate under the stylus, a train of such sparks controlled by a piezoelectric crystal produces an isolating cut approximately 75 microns wide. The isolating line may then be used to define the circuit pattern, and by measuring the resistor, cutting can be continued and terminated when the resistor lies within the design limits. The spark machining technique has now been replaced by a laser head which gives a cut width of 12 microns, allowing the production of smaller resistors of tighter tolerance, and for circuit functional adjustment to be performed. The latter becomes possible as there are no transient sparking currents in the film being measured.

The precision resistor networks made using this technique, with $\mathrm{TCR}<20 \mathrm{ppm} /{ }^{\circ} \mathrm{C}$ and tolerances of \pm 0.05 per cent absolute and 0.02 per cent ratio, can be directly packaged at this stage, or with added components be incorporated at the substrate level into more complex hybrid circuits.

\section{Thick Film Technology}

An account has already been given in this journal of the principles of thick film technology in microelectronics (3). Briefly, the thick film process uses preparations of the material to be deposited in finely divided form and mixed with controlled amounts of glass fluxes. The mixture is suspended in an organic medium. After printing the latter is burnt off during the firing cycle to leave the desired film. Conductor films use gold or other noble metals or their alloys, while resistor films can be similarly made but use combinations of noble metals and semiconducting refractory metal oxides.

This technology was introduced to Paignton about eight years ago from the United States, employing thick film resistor compositions based on palladium and conductor compositions manufactured from gold alloyed with either platinum or palladium. These 


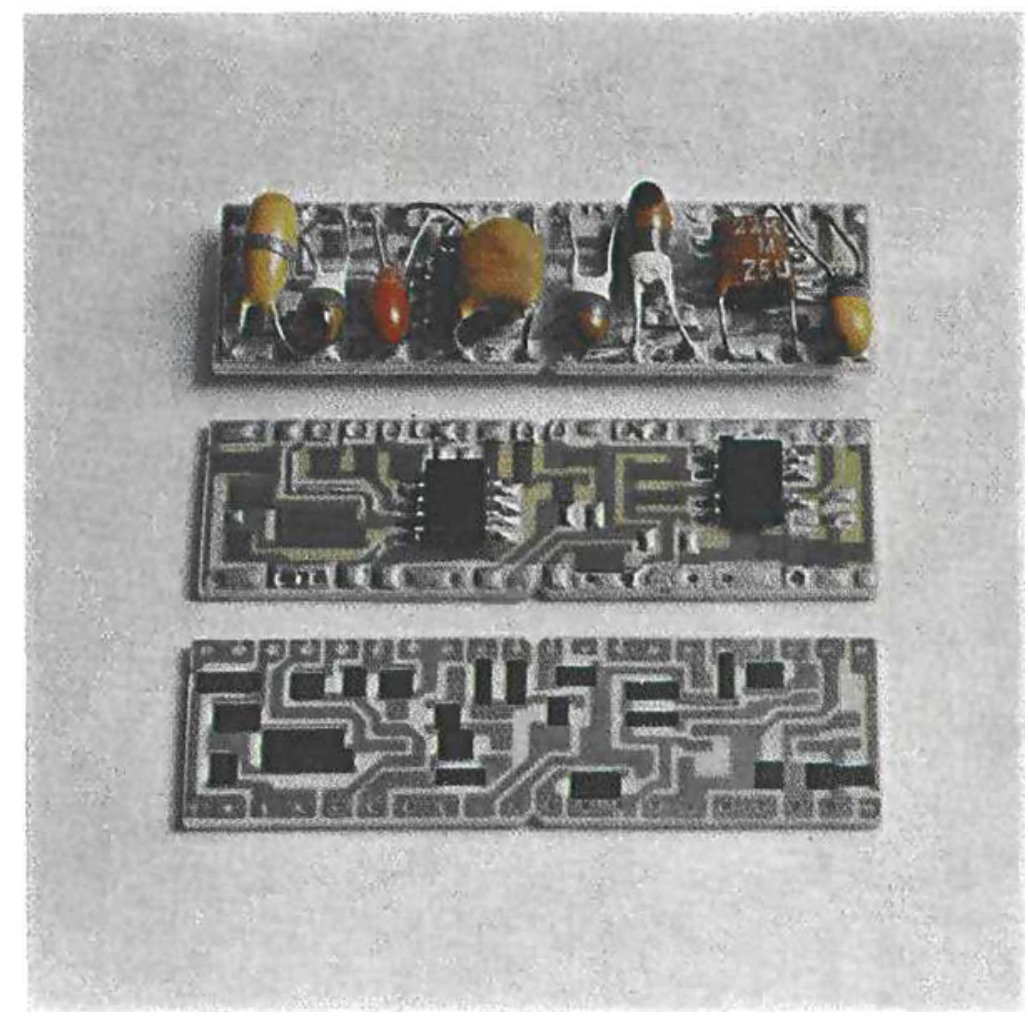

Fig. 3 Thick film eireuit providing a resistor interconnection pattern deposited on a high alumina substrate. The palladium-gold inter-connection pattern also performs the function of a printed eircuit board for attachment of conventioually packaged added components such as tantalum and ceramic capacitors and multi-semiconductor flat-packs

ponents can be built up by sequential printing and firing as seen in Fig. 3. The conductor composition is deposited first and fired at approximately $900^{\circ} \mathrm{C}$, insulating layers are fired at $850^{\circ} \mathrm{C}$ to generate crossovers, the resistor composition is deposited next and fired at $850^{\circ} \mathrm{C}$, and finally an overglaze is fired over the active parts of the component at $500^{\circ} \mathrm{C}$.

first generation materials had their problems. The resistor materials based on palladium oxide were reactive and changed their state during firing, making process control difficult.

The second generation of thick film materials saw the replacement of palladium oxide by rutheniumbased systems. To assess their suitability it was necessary to identify the precise requirements of the product as well as the electrical properties, and standard tests were devised to monitor stability under temperature and humidity variations, to evaluate voltage stresses on resistors, to analyse the structure of resistor materials, and to study the interaction of the various materials within the components.

The early conductors also had problems, suffering from leaching and reduced adhesion after the solder coating cycle. This problem was particularly prevalent for palladium-gold alloys and initiated an investigation by STL into the degradation mechanisms (4). The results of this work, in co-operation with the manufacturers, have now resulted in a much improved product being available on the market. Platinum-gold is basically free from major failure modes, but due to the high intrinsic cost of the materials its application is limited. A good understanding of the adhesion and solderability degradation mechanisms has resulted in the development of high performance and lower cost materials, and reasonable performance conductors produced from palladiumsilver alloys may be obtained.

Using the thick film materials, networks of com-
Adjustment of the fired resistors is an important feature of the technology. As in the case of thin film, the ability to make resistors to custom values optimises circuit electrical performance with design and manufacturing procedures.

The development of laser trimming systems and suitable inks has much improved the flexibility of the thick film system. Resistor tolerances have improved from \pm 2 to \pm 0.5 per cent and sizes have reduced by a factor of four. Even more important is the ability to adjust resistors in the presence of sensitive added components such as unencapsulated semiconductor devices.

\section{Hybrid Technology}

Major advances in integrated circuit design have been taking place in parallel with the film circuit development, enabling complete circuit function to be achieved in a single silicon chip. The film circuit technologies have opened up an important area of compatibility with the monolithic system, providing an interconnection pattern directly compatible with the semiconductor integrated circuit at the chip level. The resultant hybrid assembly is then packaged as a modular function. The hybrid assembly may therefore contain a thin film precision resistor network, thick film resistors and multi-layer interconnection pattern, chip integrated circuits and miniature ceramic capacitors, providing a full range of choice and flexibility in designing the hybrid circuit. 
Fig. 4. Examples of the mixture of thin and thick film substrate within the hybrid package. A simple thick film gold semiconduetor interconnection pattern meets the need for high processing temperatures and low thermal impedance necessary for power dissipating devices. The thin film substrate meets the needs of close tolerance high specification resistors. The circuit elements are interconnected using 0.001 inch gold wire and the gold-plated package hermetically sealed to give a high degree of environmental protection

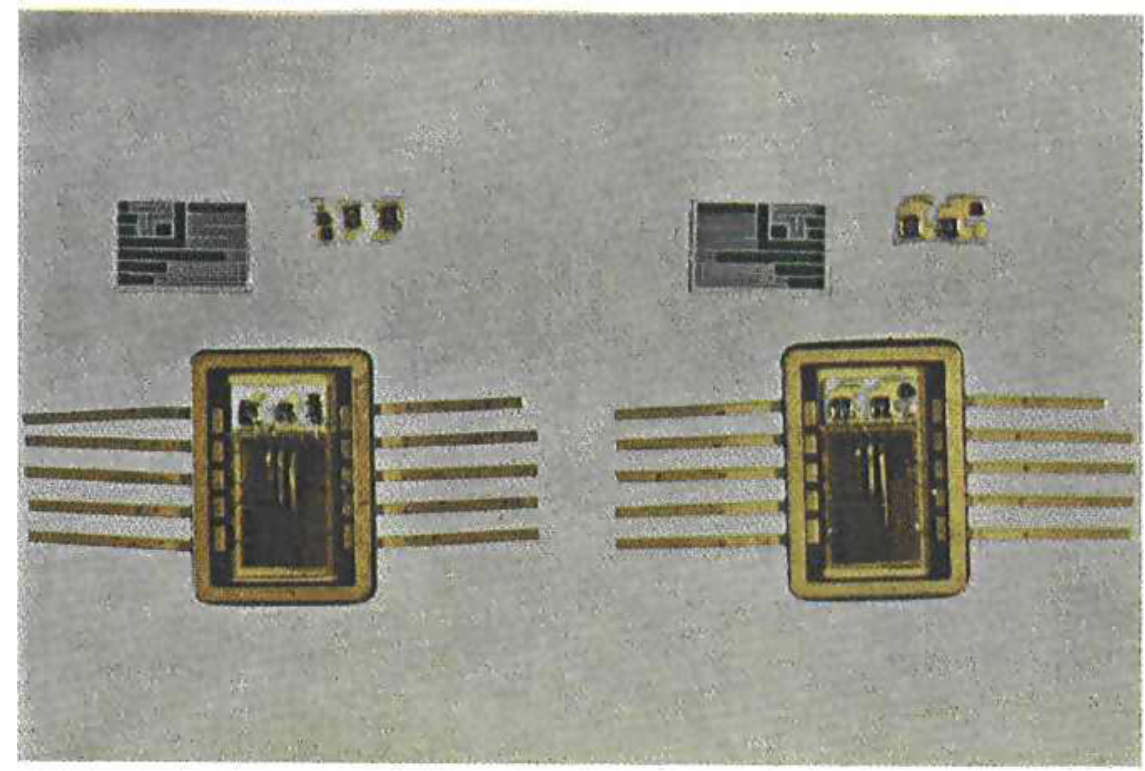

Soldering and brazing has historically been the preferred mounting technique for the majority of added components, but this is now being replaced in many cases by conductive epoxy resins heavily loaded with gold or silver (5). Highly adherent bonds of low resistance are formed, capable of operating reliably over the full military range of -55 to $+150^{\circ} \mathrm{C}$.

Interconnection of the semiconductor chips into the circuit, and the substrate into the package, is achieved by ultrasonic wire bonding using 0.001 inch diameter gold wire. The gold wire has high conductivity and current carrying capacity and forms highly reliable bonds to the semiconductor metallisation (usually aluminium) and the thick film interconnection patterns which is normally of pure gold.

The composite hybrid is then packaged in a form depending on the application and the components used. Where semiconductor chips are present the package is usually hermetic and may be either a flat-pack or dual-in-line can. Both packages are normally gold plated to provide compatible bonding metallurgies and a corrosion-resistant coating capable of meeting full military and medical environments. An example is shown in Figure 4.

\section{Applications}

Hybrid circuit manufacture at Paignton is primarily concerned with meeting industrial, military and medical custom applications.

Fig. 4 is well representative of the military products, where sophisticated airborne electronic systems demand small size, low weight and high reliability while operating under extreme environmental stresses.
Fig. 5 The use of hybrids in medical electronics is illus. trated in the implanted pace maker. Thick film and thin film can be combined to give optimum electronic perform. ance and reliability in service

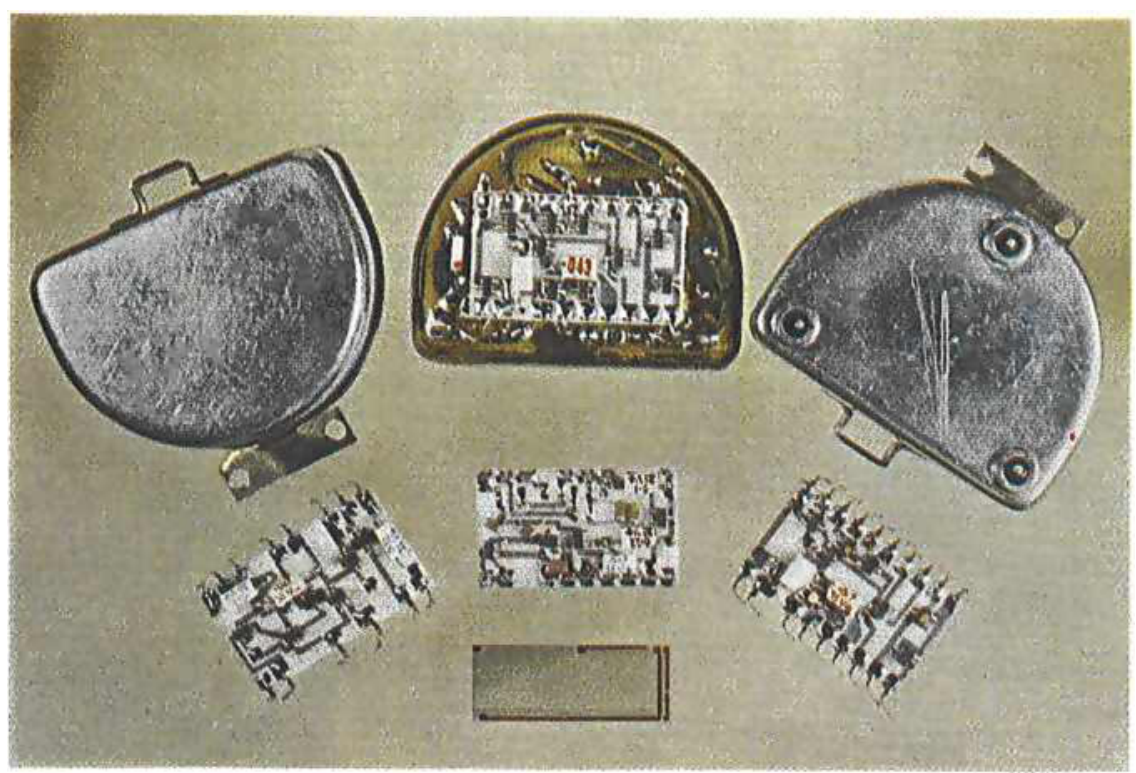


The use of hybrids becomes a significant feature of new medical electronic developments. Patient surveillance systems need to be portable, preferably small in size and weight and to operate off battery supplies. These features must be achieved with a high level of reliability, aspects which can readily be met by hybrid circuits.

A classic use of the hybrid circuit is the implanted heart pacemaker, shown in Fig. 5. Thin film and thick film technologies are combined to give optimum electronic and reliability of performance in this vital component.

\section{Summary}

A range of technologies has been developed to meet the requirements of the professional markets, where high performance, i.e., small size, environmental range, reliability etc., are key features. Gold features extensively in all of the products; in thin and thick film metallisations, in the conductive epoxies and solders, the wire used for making component interconnections and as a final coating of the total package. In all cases the presence of gold assists in the fabrication and subsequent performance of the microelectronic assemblies.

\section{References}

1 E. E. Smith and S. G. Ayling, Sputtered Dielectric Capacitors, 1962 Electronic Components Conference, Washington, U.S.A.

2 S. G. Ayling, T. A. Askwith and M. Tarr, The Manufacture of Close Tolerance Miniature Silica Film Dielectric Capacitors, Inter-Nepcon 1971

3 R. G. Finch, Gold in Thick Film Hybrid Microelectronics, Gold Bulletin, 1972, 5, (2), 26

4 W. A. Crosland and L. Hailes, Thick Film Conductor Adhesion Reliability, Solid State Technol., 1971, 42

5 P. C. G. Nolan, Resin Attachment of Semiconductor Dice on to Film Circuits, Microelectrics and Reliability, 1973, 12, pp. 235-241

\section{A New Gold Metallisation System for Beam Lead Technology}

Beam lead technology, developed by Bell Telephone laboratories in 1966, has permitted the fabrication of high frequency semiconductor devices and integrated circuits with very low parasitic capacitance as well as improved resistance to severe environments such as corrosive atmospheres or high acceleration.

The novel features of the technology were:

(a) the replacement of aluminium metallisation, with its attendant problems of junction degradation, corrosion and electromigration, by gold metallisation;

(b) the development of an etching process which permits the isolation of devices yet allows them to be interconnected by the "beam leads", cantilevers of electroplated gold which extend beyond the edges of the device.

Widespread adoption of the technology has, to some extent, been limited by the complexity of the operations involved, with the consequence of a relatively poor yield in production.

In a development now reported by Yoshiaki Nakamura of the Nippon Electric Co., Tokyo, a layer of chromium silicide is substituted for the original layer of platinum silicide used to make ohmic contact to the silicon (Nippon Electric Co. Research $\mathcal{E}$ Development, $1973,(31), 64-71)$. Another feature of the new process is that the surface of a subsequent layer of chromium is "passivated" by buffing with a moistened cotton

The improved electrodeposited gold contact fingers on an integrated circuit made by Nippon Electric. The new process permits the manufacture of beam leads using only two vacuum deposition stages instead of the three normally required ball. This treatment is reported to produce a hydrophobic surface on the exposed metal which prevents the adherence of gold during electroplating, and also to improve the adhesion between the electroplated gold and the platinum contact fingers. For this reason it is possible to increase the thickness of gold plating on the contact fingers with a consequent improvement in the high frequency gain of the devices.

It is possible entirely to dispense with one stage of vacuum processing, thus improving the yield from the production process. It is also claimed that the substitution of chromium silicide for platinum silicide results in a lower and more stable contact resistance. It is premature to decide whether improved yields will be achieved when the new system enters bulk production and whether the improved ageing characteristics will actually result in higher reliability, but it is a most interesting development that will be of widespread application.

G. J. H.

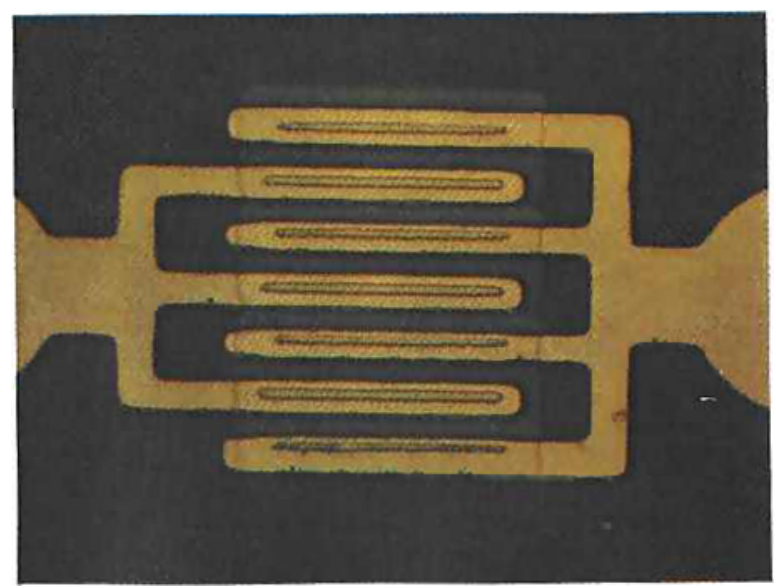

